\title{
Morphology and Viscoelastic Properties of Star-Shaped Styrene-Butadiene Radial Block Copolymers
}

\author{
Toshikazu TAKIGAWA, Yasuhiko OHTA, Shinji ICHIKAWA, \\ Takahiko KoJIMA, Akira TANAKA,* \\ and Toshiro MASUDA
}

\author{
Research Center for Medical Polymers and Biomaterials, \\ Kyoto University, Kyoto 606, Japan \\ *Department of Polymer Chemistry, Kyoto University, \\ Kyoto 606, Japan
}

(Received September 16, 1987)

\begin{abstract}
Four samples of star-shaped styrene-butadiene block copolymers were prepared by anionic polymerization. Samples have been characterized in terms of molecular weight, molecular weight distribution and coupling ratio (number of branches per molecule). Films of the samples were prepared by casting from cyclohexane and 9:1 tetrahydrofuran (THF)/methyl ethyl ketone (MEK) mixture. The morphology, and mechanical and dynamic viscoelastic properties have been examined in solid state. The morphology of the films of the radial block copolymers is affected by the primary chain structures, molecular weight and casting solvent. The mechanical and dynamic viscoelastic properties of the films are characteristic of the morphology. The relations among primary chain structure, morphology and viscoelastic properties are discussed in detail on the basis of the experimental results.

KEY WORDS Styrene / Butadiene / Radial Block Copolymer / Glass Transition / Microdomain / Morphology / Viscoelastic Property / Solid State /
\end{abstract}

The extensive studies on block copolymers have been done and some of them have been used as industrial materials. Styrene-butadiene-styrene block copolymers (SBS), for example, are utilized as thermoplastic elastomers. In case of linear AB type diblock and linear ABA type triblock copolymers, ${ }^{1-5}$ it is well-known that the morphology in the solid state is affected not only by the composition of $A$ and B blocks but also by the type of solvents for casting. In addition to these works, the dynamic viscoelastic properties for linear styrene-butadiene (SB) and linear styrenebutadiene-styrene (SBS) block copolymers were investigated by many authors, ${ }^{4-6}$ and the relations between the morphology and the dynamic viscoelastic properties have become fairly clear.
On the other hand, the studies on the morphology and the viscoelastic properties for radial block copolymers ${ }^{11-17}$ are not so many as those for the linear copolymers because of the difficulty in obtaining monodisperse samples, and therefore the relations between the morphology and the viscoelastic properties for the radial block copolymers remain still ambiguous.

The aim of this study is to investigate the relations among the primary chain structures, morphology, and mechanical/viscoelastic properties by examining how the primary chain structures of the radial block copolymers and the casting solvents affect the morphology, and how the dynamic viscoelastic and mechanical properties are influenced by the morphology. 


\section{EXPERIMENTAL}

Four samples of styrene (S)-butadiene (B) block copolymers were synthesized by an anionic polymerization method and were employed in this study. The sample code, numberand weight-average molecular weights $\left(\bar{M}_{n}\right.$ and $\left.\bar{M}_{w}\right)$ and the ratio $\left(\bar{M}_{w} / \bar{M}_{n}\right)$ for the radial block copolymers, the length and composition of the branch measured in $\bar{M}_{n}$, and the coupling ratio $(P$, average number of branches per molecule) are tabulated in Table I. Two types of star-molecules in different primary chain structure, BSH and SBH series, appear in this table. The $\mathrm{SBH}$ series $(\mathrm{SBH} 1, \mathrm{SBH} 2$, and SBH3) were polymerized by two-stage sequential addition of styrene and butadiene monomers at a low temperature near $0^{\circ} \mathrm{C}$, using cyclohexane as a solvent and sec-BuLi as an initiator, and by coupling living ends with 1,2-bis(trichlorosilylethane) dissolved in $n$-hexane at $50^{\circ} \mathrm{C}$. Polymer concentration for the coupling reaction was $50 \mathrm{gl}^{-1}$ and the molar ratio of polymer to the coupling reagent was $1: 2$. BSH1 was prepared by a similar way except for the reverse sequential addition of monomers. Small amounts of linear precursors [polystyrene (PS) and linear SB block copolymers for SBH series, and polybutadiene (PB) and linear BS block copolymer for BSH1] were taken out from the polymerization systems on each stages and the molecular weight of each precursor was measured in order to characterize the primary chain structure of the star-shaped radial block copolymers. Number-average molecular weights of the star-shaped copolymers and their linear precursors were measured by using High Speed Membrane Osmometer (Meclolab Model 502). The ratio of molecular weights, $\bar{M}_{w} / \bar{M}_{n}$, for the star-shaped copolymers was measured using a gel permeation chromatograph (Waters Model 200). $\bar{M}_{w}$ was calculated as a product of $\bar{M}_{n}$ and $\left(\bar{M}_{w} / \bar{M}_{n}\right)$. The coupling ratio was evaluated from the ratio of $\bar{M}_{\mathrm{n}}$ of the star-shaped copolymers to that of a branch. It has been reported $^{18}$ that microstructure of polybutadiene prepared by the same method as described above is $50.1 \%$ of $1,4-$ trans, $43.1 \%$ of $1,4-$ cis, and $6.8 \%$ of vinyl.

Transmission electron microscopy was carried out at the acceleration voltage of electron beam of $100 \mathrm{kV}$. The film specimens used for the measurements of mechanical and dynamic viscoelastic properties were prepared by casting from dilute solutions. Cyclohexane (Cy), preferential solvent for $\mathrm{PB}$, and 9/1 tetrahydrofuran (THF)/methyl ethyl ketone (MEK) mixture $(T / M)$, nonpreferential solvent, were used as casting solvents. Tensilon (Toyo Baldwin UTM-4L) was used to measure extentional properties of the film specimens at various temperatures. Dynamic viscoelastic properties of the samples were measured using Rheovibron (Toyo Baldwin DDV-II-C)

Table I. Number- and weight-average molecular weights and the ratio for radial block copolymers, length and composition of the branch ( $\mathrm{S}$, weight percentage of styrene) measured in number-average molecular weight and coupling ratio ( $P$, average number of branches per molecule)

\begin{tabular}{|c|c|c|c|c|c|c|c|c|}
\hline \multirow{2}{*}{ Sample } & \multicolumn{3}{|c|}{ Radial block copolymer } & \multicolumn{3}{|c|}{ Branch $\bar{M}_{n} \times 10^{-4}$} & \multirow{2}{*}{$\mathrm{S} / \%$} & \multirow{2}{*}{$\mathrm{P}$} \\
\hline & $\bar{M}_{n} \times 10^{-4}$ & $\bar{M}_{w} / \bar{M}_{n}$ & $\bar{M}_{w} \times 10^{-4}$ & SB & PS & PB & & \\
\hline BSH1 & 31.6 & 1.18 & 37.2 & 5.93 & $4.23^{\mathrm{a}}$ & 1.70 & 71.3 & 5.3 \\
\hline BSH1 & 25.7 & 1.13 & 29.0 & 5.64 & 4.63 & $1.01^{\mathrm{a}}$ & 82.1 & 4.6 \\
\hline BSH2 & 40.4 & 1.17 & 47.2 & 9.56 & 7.77 & $1.79^{\mathrm{a}}$ & 81.3 & 4.2 \\
\hline BSH3 & 43.9 & 1.19 & 52.1 & 7.47 & 3.39 & $4.08^{\mathrm{a}}$ & 45.4 & 5.9 \\
\hline
\end{tabular}

a Calculated value, a difference between $\bar{M}_{n}$ of SB and PS (or PB). 
at $110 \mathrm{~Hz}$ in a temperature range of -160 $110^{\circ} \mathrm{C}$.

\section{RESULTS}

\section{Morphology}

Figure 1 shows the transmission electron micrographs of the films of BSH1 cast from $T / M$ solution ( $T / M$ film) and from $C y$ solution (Cy film). BSH1 consists of inner core of PS block chains and outer shell of PB blocks. We intended to prepare BSH1 with the same length of branch, composition and coupling ratio as $\mathrm{SBH} 1$, but differently in primary structure from SBH1. Because of the difficulty in controlling the conditions for an anionic polymerization and a coupling reaction, however, BSH1 has slightly lower composition of PS and larger coupling ratio than SBH1, as seen from Table $\mathrm{I}$. The white region in
BSH L $-T / M$

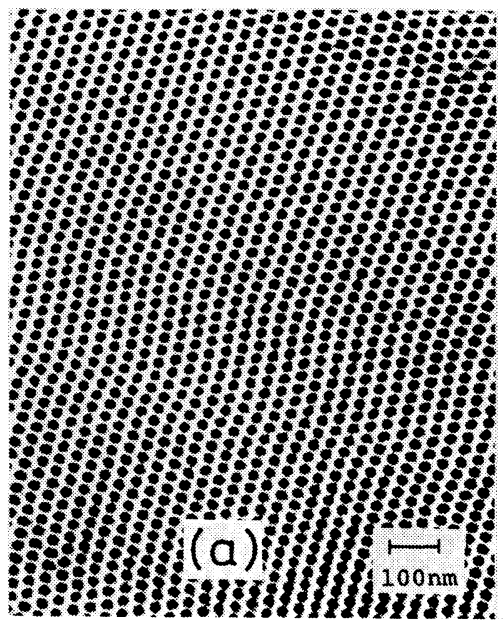

BSH1-Cy

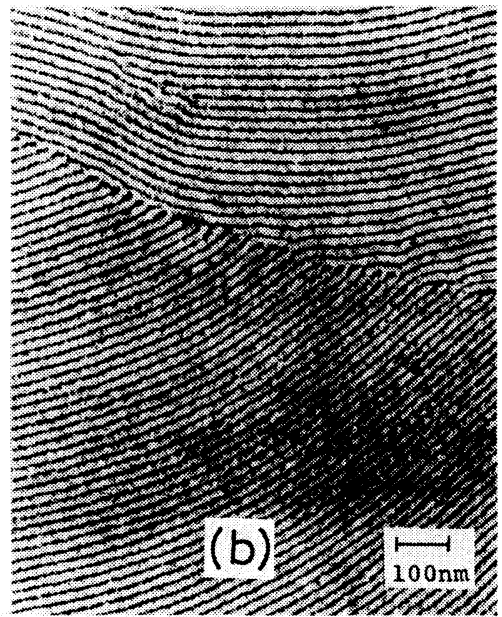

Figure 1. Transmission electron micrographs of BSH1 cast from (a) $\mathrm{T} / \mathrm{M}$ and (b) Cy.

$\mathrm{SBH} 2-\mathrm{T} / \mathrm{M}$

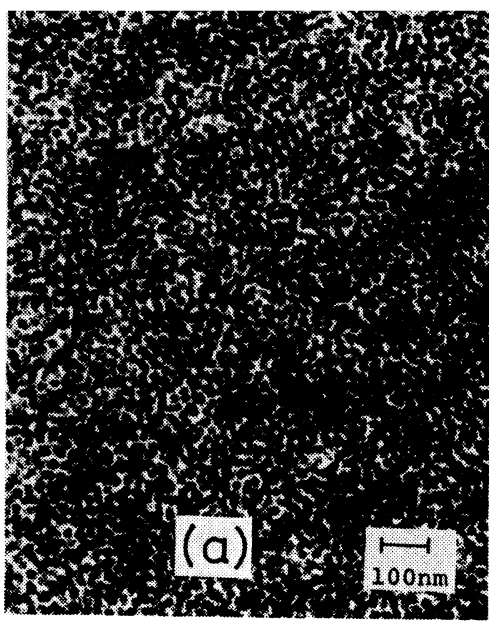

$\mathrm{SBH} 2-\mathrm{CY}$

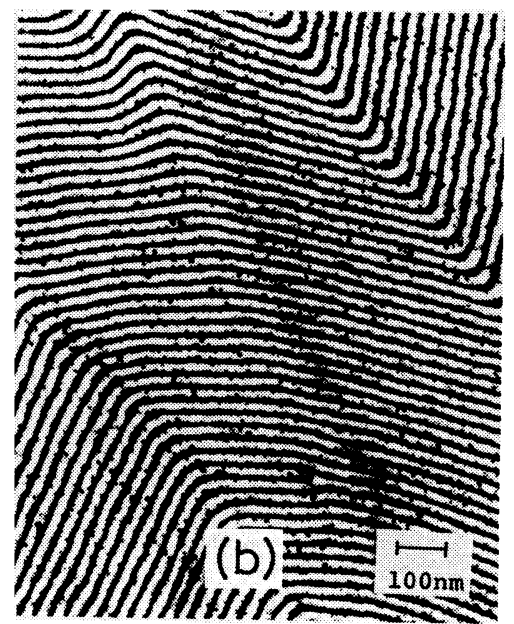

Figure 2. Transmission electron micrographs of $\mathrm{SBH} 2$ cast from (a) $\mathrm{T} / \mathrm{M}$ and (b) $\mathrm{Cy}$. 
electron micrograph pictures corresponds to PS domains and the black to PB domains stained by $\mathrm{O}_{\mathrm{s}} \mathrm{O}_{4}$. The $\mathrm{T} / \mathrm{M}$ film shows the cylindrical morphology where $\mathrm{PB}$ forms the cylindrical domains in PS matrix. The $\mathrm{Cy}$ film shows the lamellar morphology seen from Figure 1 (b). Seeing this figure carefully, we can find that some parts of the lamellae are pinched in PS domains. This region would be expected to show a different viscoelastic behavior from the complete ordered lamellar morphology, as discussed later.

The similar micrographs of the films of SBH2 are shown in Figure 2. The sample $\mathrm{SBH} 2$ is similar to $\mathrm{BSH} 1$ in the composition and number of branches, but has a longer length of the branch, and an inverse primary structure of BSH1. Though the $\mathbf{T} / \mathbf{M}$ film shows the cylindrical morphology, we can not observe pure PS domains, but only the gray and the black (pure PB) regions. The gray region can be considered as a PS phase in which the radial block copolymers are molecularly dispersed, as will be discussed later. The Cy film shows again the lamellar morphology.

Figure 3 shows the similar micrographs for the films of SBH1 which has the same number of branches, composition and primary chain structure as, and a shorter length of branch than, SBH2. The T/M film shows the cylindrical morphology and has the gray parts similar to that of SBH2. The Cy film of SBH1 shows disordered lamellar morphology, which includes regions of ordered lamellae, pinched-in lamellae, disordered PB cylinders and gray region. For the $\mathrm{Cy}$ and the $\mathrm{T} / \mathrm{M}$ films of $\mathrm{SBH} 3$ having higher $\mathrm{PB}$ content, we could not get the micrographs, because they were too soft to prepare thin sections.

\section{Dynamic Viscoelastic Properties}

Figure 4 shows the temperature dispersions of dynamic Young's modulus $\left(E^{\prime}\right)$, loss modulus $\left(E^{\prime \prime}\right)$ and loss tangent $(\tan \delta)$ of the T/M and the Cy films of BSH1. The peaks of $E^{\prime \prime}$ are observed at $-100^{\circ} \mathrm{C}$ and $100^{\circ} \mathrm{C}$ for the $\mathrm{T} / \mathrm{M}$ film. These peaks correspond to the glass transitions of the PB domains and the PS domains, respectively. For the PB homopolymer taken out from the polymerization system of the star-shaped radial block copolymers employed in this study, the glass transition temperature $\left(T_{\mathrm{g}}\right)$ was $c a .-65^{\circ} \mathrm{C}$, and it is much higher than that of the PB domains of the $\mathrm{T} / \mathrm{M}$ film of BSH1. This difference in $T_{\mathrm{g}}$
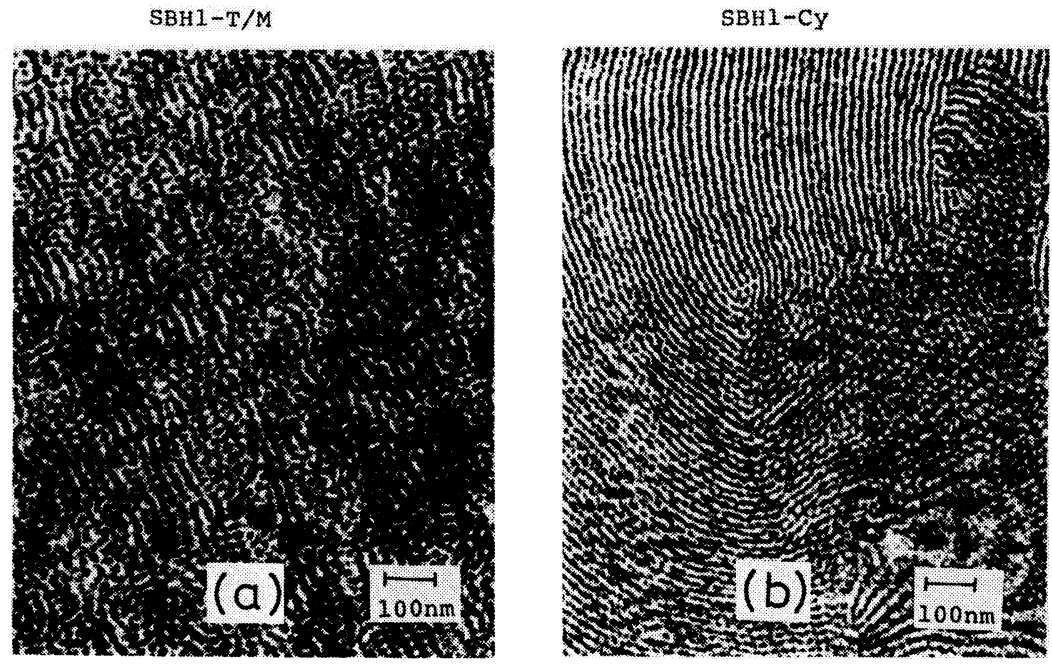

Figure 3. Transmission electron micrographs of $\mathrm{SBH} 3$ cast from (a) $\mathrm{T} / \mathrm{M}$ and (b) $\mathrm{Cy}$. 
SB Star Block Copolymers

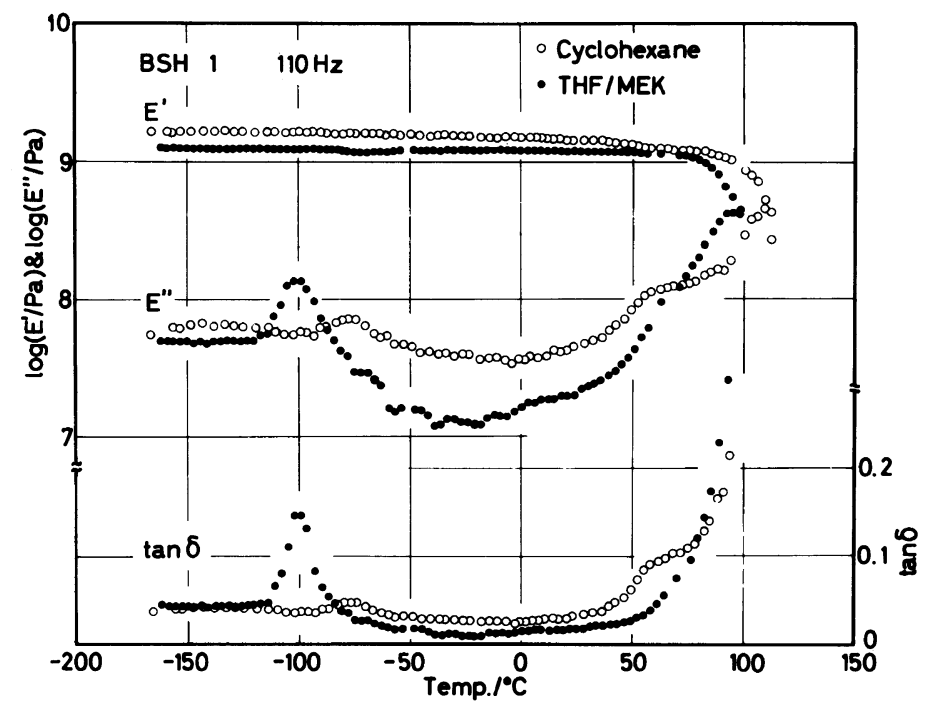

Figure 4. Temperature dispersions of dynamic Young's modulus $\left(E^{\prime}\right)$, loss modulus $\left(E^{\prime \prime}\right)$ and loss tangent $(\tan \delta)$ of $\mathrm{BSH} 1$ cast from $\mathrm{T} / \mathrm{M}(\bigcirc)$ and $\mathrm{Cy}(\mathrm{O})$.

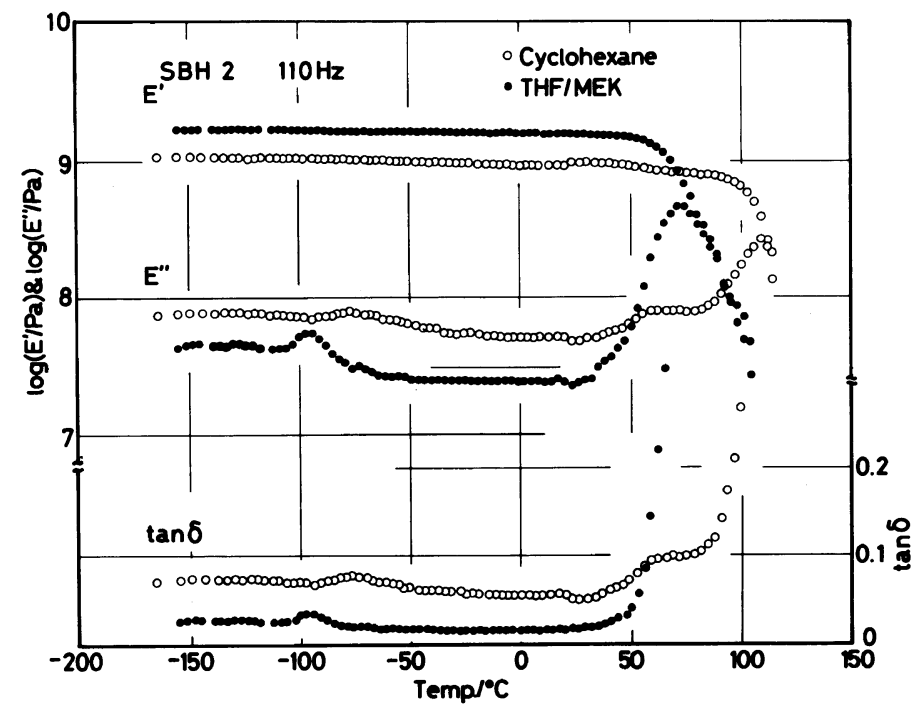

Figure 5. Temperature dispersions of dynamic Young's modulus $\left(E^{\prime}\right)$, loss modulus $\left(E^{\prime \prime}\right)$ and loss tangent $(\tan \delta)$ of $\mathrm{SBH} 2$ cast from $\mathrm{T} / \mathrm{M}(\mathbf{O})$ and $\mathrm{Cy}(\mathrm{O})$.

is discussed later. The peaks of $E^{\prime \prime}$ for the $\mathrm{T} / \mathrm{M}$ film. The $E^{\prime \prime} v s$. temperature curve of Cy film are observed at $-75^{\circ} \mathrm{C}$ and $110^{\circ} \mathrm{C}$, the Cy film shows a higher plateau in the temand the shoulder of $E^{\prime \prime}$ at $60^{\circ} \mathrm{C}$. The highest peak corresponds to the $T_{\mathrm{g}}$ of the PS domains. The lowest peak, corresponding to the $T_{\mathrm{g}}$ of the PB domains, is located at the higher temperature side than that of the perature range between two $E^{\prime \prime}$ peaks, while that of the $T / M$ film shows the minimum in this range.

A comparison of the $\mathrm{T} / \mathrm{M}$ and the $\mathrm{Cy}$ films of $\mathrm{SBH} 2$ are shown in Figure 5. The highest 


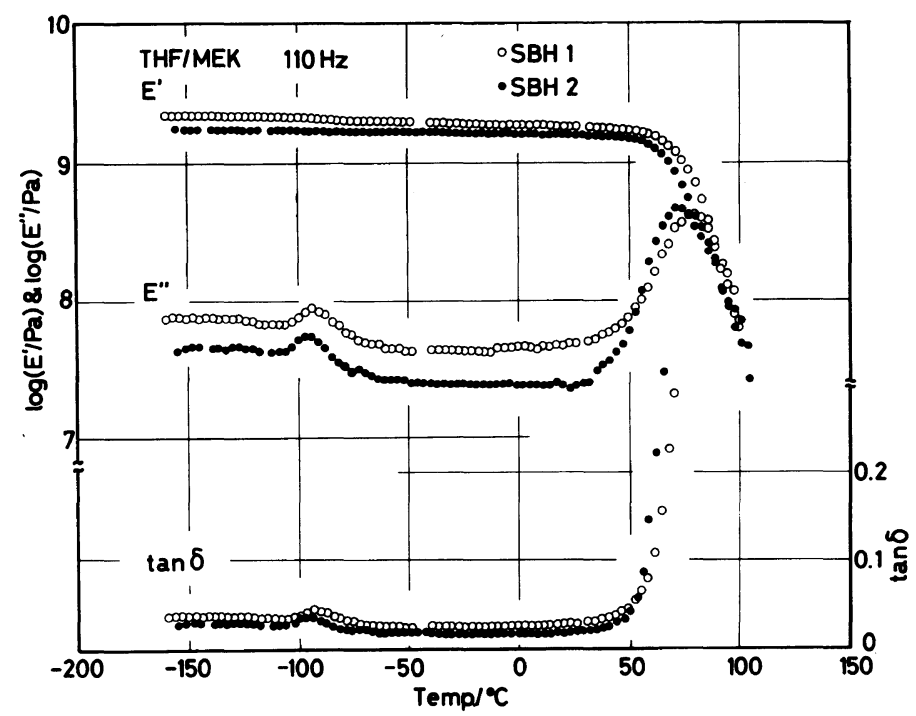

Figure 6. Temperature dispersions of dynamic Young's modulus $\left(E^{\prime}\right)$, loss modulus $\left(E^{\prime \prime}\right)$ and loss tangent $(\tan \delta)$ of SBH1 (O) and $\mathrm{SBH} 2(\bigcirc)$ cast from $\mathrm{Cy}$.

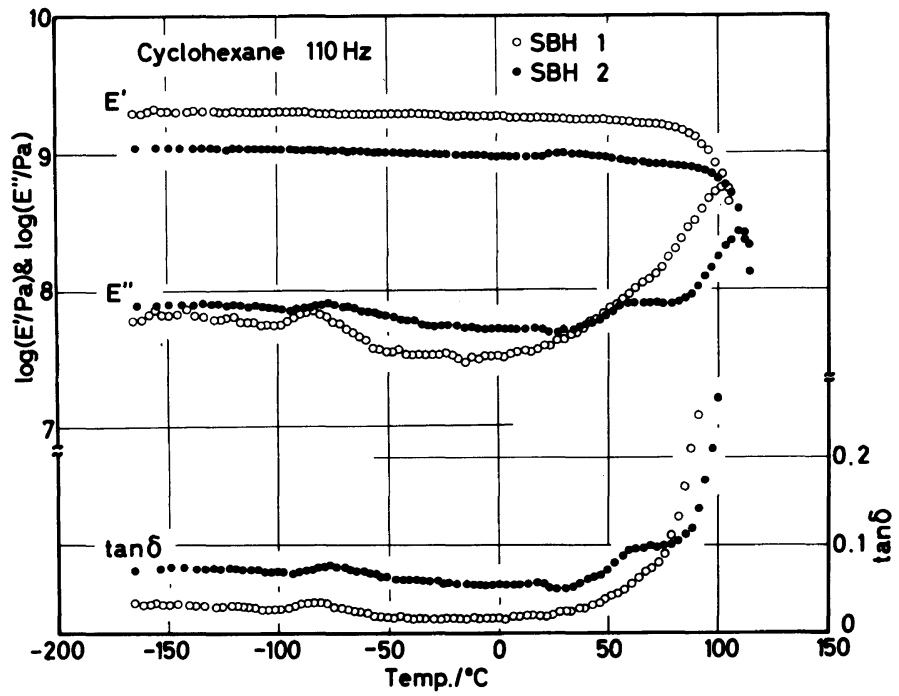

Figure 7. Temperature dispersions of dynamic Young's modulus $\left(E^{\prime}\right)$, loss modulus $\left(E^{\prime \prime}\right)$ and loss tangent $(\tan \delta)$ of SBH1 (O) and SBH2 (O) cast from T/M.

peak of $E^{\prime \prime}$ is observed at $80^{\circ} \mathrm{C}$ for the $\mathrm{T} / \mathrm{M}$ film. However, the $T_{\mathrm{g}}$ is lower than that of the PS domains of the T/M film of BSH1 by $c a$. $20^{\circ} \mathrm{C}$. The lowest peak which corresponds to the $T_{\mathrm{g}}$ of the PB domains is observed at $-95^{\circ} \mathrm{C}$. The $E^{\prime \prime} v s$. temperature curve for the $\mathrm{T} / \mathrm{M}$ film in the temperature range between two $E^{\prime \prime}$ peaks shows a higher plateau similar to that of the Cy film of BSH1. For the Cy film of $\mathrm{SBH} 2$, the shape of the $E^{\prime \prime} v s$. temperature curve is quite similar to that of the Cy film of BSH1.

Figure 6 shows the viscoelastic functions for the $\mathrm{T} / \mathrm{M}$ films of $\mathrm{SBH} 1$ and $\mathrm{SBH} 2$. In the 


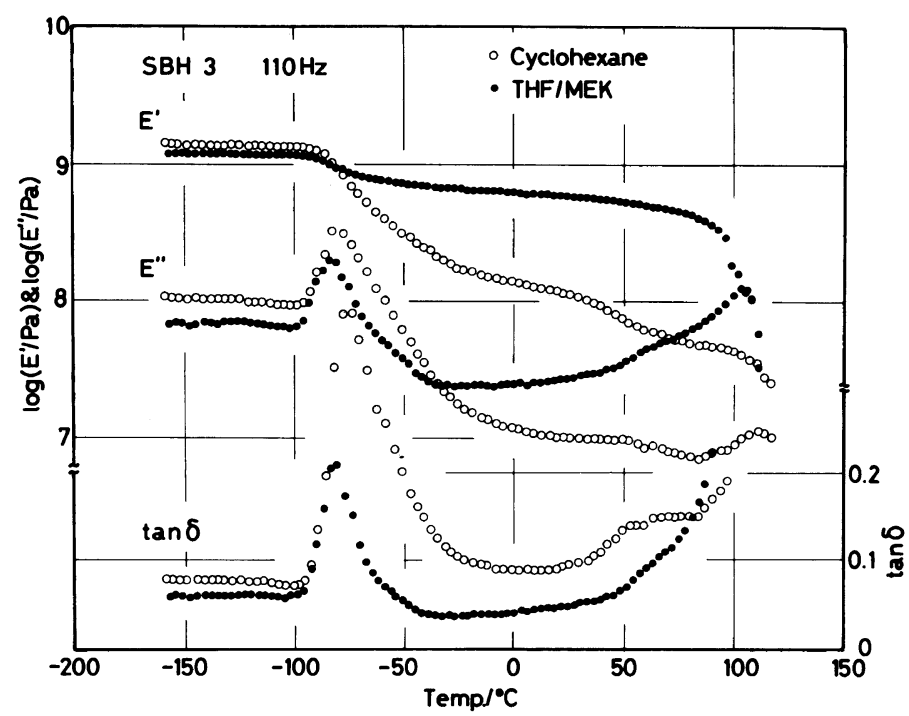

Figure 8. Temperature dispersions of dynamic Young's modulus $\left(E^{\prime}\right)$, loss modulus $\left(E^{\prime \prime}\right)$ and loss tangent $(\tan \delta)$ of $\mathrm{SBH} 3$ cast from $\mathrm{T} / \mathrm{M}(\bigcirc)$ and $\mathrm{Cy}(\mathrm{O})$.

$E^{\prime \prime} v s$. temperature curve for $\mathrm{SBH} 1$, the highest peak is located at $80^{\circ} \mathrm{C}$ and is at the almost same position as that for $\mathrm{SBH} 2$. The lowest peak of $E^{\prime \prime}$ for SBH1 is also at the almost same position as for $\mathrm{SBH} 2$. The $E^{\prime \prime} v s$. temperature curves for both $\mathrm{SBH} 1$ and $\mathrm{SBH} 2$ show higher plateau in the temperature range between two $E^{\prime \prime}$ peaks.

In Figure 7, the similar plots for the Cy films of SBH1 and SBH2 are shown. The $E^{\prime \prime} v s$. temperature curve in the higher temperature range for $\mathrm{SBH} 1$ shows a broader peak at $100^{\circ} \mathrm{C}$, while that for $\mathrm{SBH} 2$ shows a peak at $110^{\circ} \mathrm{C}$ and a shoulder at $60^{\circ} \mathrm{C}$. The lowest peak for $\mathrm{SBH} 1$ is at the lower temperature side than that for SBH2, but these two curves show higher plateau in the temperature range between two $E^{\prime \prime}$ peaks.

Figure 8 shows the similar plots of the $T / M$ and the Cy films of SBH3. The $E^{\prime}$ of the $\mathrm{Cy}$ film decreases steeply at $-75^{\circ} \mathrm{C}$ with increasing temperature, and the $\mathrm{T} / \mathrm{M}$ film keeps relatively higher values of $E^{\prime}$ in the high temperature region. For both films, the peaks of $E^{\prime \prime}$ and $\tan \delta$ are observed at $-75^{\circ} \mathrm{C}$ and $105^{\circ} \mathrm{C}$, and the shoulder at $50^{\circ} \mathrm{C}$.

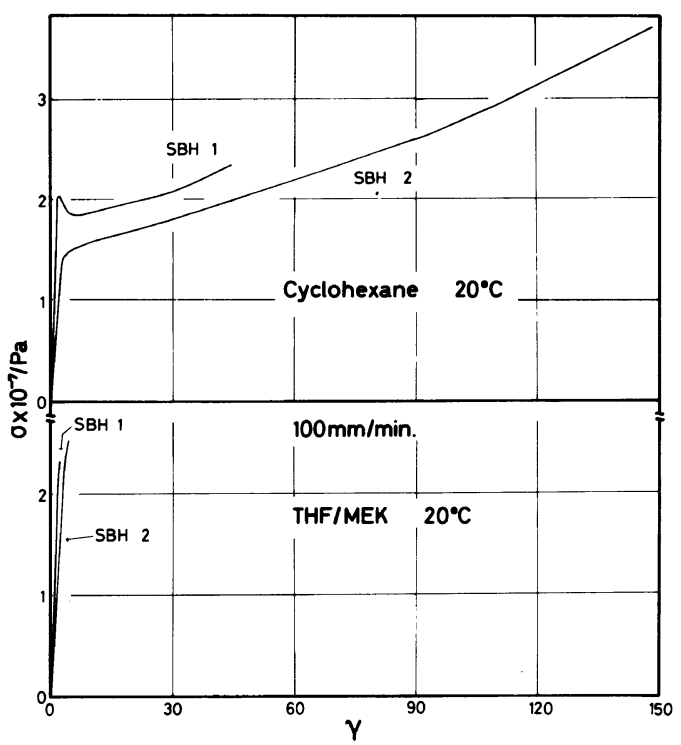

Figure 9. Stress-strain curves for $\mathrm{SBH} 1$ and $\mathrm{SBH} 2$ cast from $T / M$ and $C y$.

\section{Stress-Strain Behavior}

Figure 9 shows the tensile stress $(\sigma)$-strain $(\gamma)$ curves of the T/M and the Cy films of SBH1 and $\mathrm{SBH} 2$. In both $\mathrm{Cy}$ and $\mathrm{T} / \mathrm{M}$ films, the Young's modulus of SBH1 is nearly equal to 


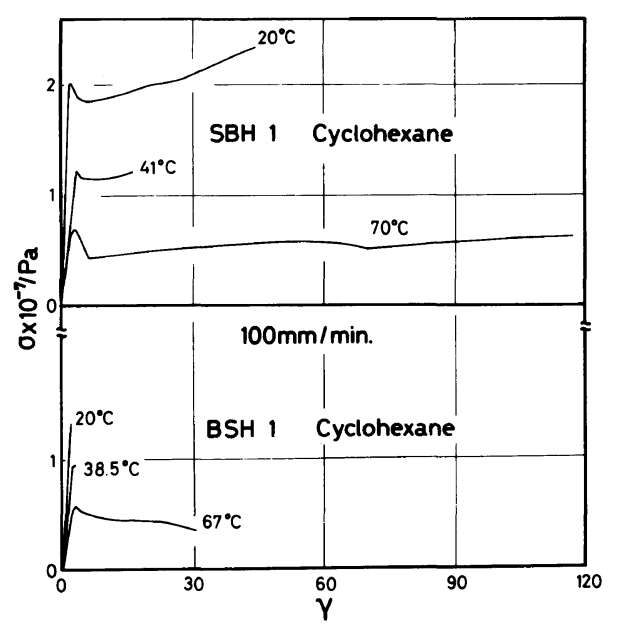

Figure 10. Stress-strain curves for SBH1 and SBH1 cast from $\mathrm{Cy}$.

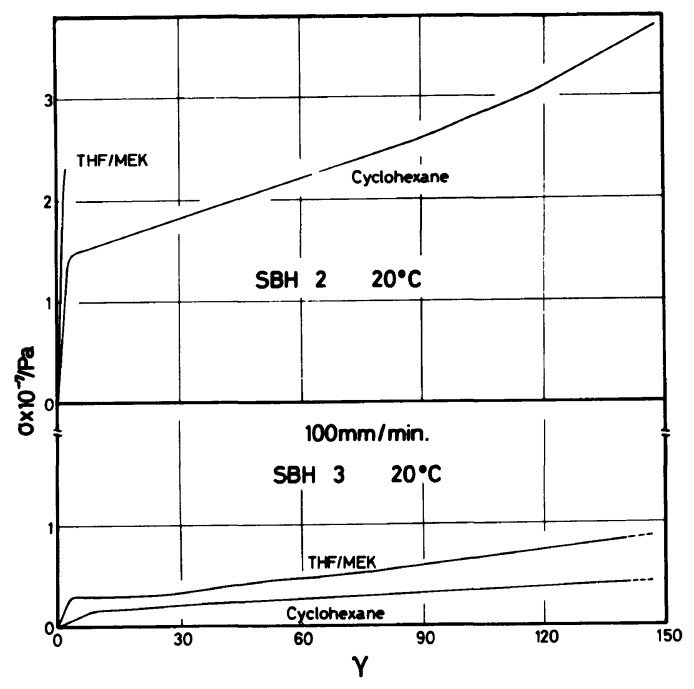

Figure 11. Stress-strain curves for $\mathrm{SBH} 2$ and $\mathrm{SBH} 3$ cast from $\mathrm{Cy}$.

that of SBH2. On the other hand, the failure strain of the $\mathrm{Cy}$ film of $\mathrm{SBH} 1$ and $\mathrm{SBH} 2$ is larger than that of the corresponding $T / M$ films.

Figure 10 shows the similar curves of the $\mathrm{Cy}$ films of BSH1 and $\mathrm{SBH} 1$ at various temperatures. At almost the same temperature, the Young's modulus of BSH1 equals that of SBH1, but the latter sample shows larger failure strain than the former. Similar comparison between the $\mathrm{T} / \mathrm{M}$ films of $\mathrm{BSH} 1$ and SBH1 could not be done because of the brittleness of the BSH1 film specimen.

Figure 11 shows the similar curves of the $\mathrm{Cy}$ and the T/M films of SBH2 and SBH3. SBH3 has almost the same number of branches, molecular weight of a branch and primary chain structure as, but are different in composition from, SBH2. The failure strain of $\mathrm{SBH} 3$ is very large compared with that of $\mathrm{SBH} 2$, and the yield stress is much smaller than that of SBH2 in both $\mathrm{T} / \mathrm{M}$ and $\mathrm{Cy}$ films.

\section{DISCUSSION}

\section{Morphology of the S-B Radial Block Co- polymers}

From the careful observation of the micrographs of the $T / M$ and the $C y$ films of the star-shaped radial block copolymers in Figures $1-3$, the morphology can be classified into the following four categories. (1) The first is the ordered cylindrical morphology observed in the $\mathrm{T} / \mathrm{M}$ film of $\mathrm{BSH} 1$, which consists of continuous PS (white) domains, cylinder-like PB (black) domains and their interphase region. (2) The second is the disordered cylindrical morphology observed in the T/M films of SBH1 and SBH2. This morphology consists of the cylindrical PB domains (black region), PS phase which looks gray, and the interphase. (3) the third is the ordered lamellar morphology observed in the Cy films of BSH1, and $\mathrm{SBH} 2$, and it consists of lamellar PB and PS domains, and the interphase region. (4) The last is the disordered lamellar morphology observed in the Cy film of SBH1. We can see ordered lamellar and disordered cylindrical parts.

It has been reported ${ }^{19}$ theoretically for linear diblock and triblock copolymers that the thermodynamically stable morphology is controlled by the volume ratio of the components under the condition of constant degree of polymerization. From the phase diagram for 
linear S-B block copolymers ${ }^{20}$ at $90^{\circ} \mathrm{C}$, the linear S-B block copolymers, having the same composition as the star-shaped copolymers employed in this study except SBH3 and the equal molecular weight to the branch, show the ordered cylindrical morphology in equilibrium state (thermodynamically most stable state) at $90^{\circ} \mathrm{C}$. The results would be the same at room temperature. How the number of branches affects the morphology is not yet clear, but it might be mainly influenced by the formation of the spherical cores where the chains are over-crowded..$^{21,22}$ de la Cruz et $a l^{23}$ have recently proposed the theory of microphase separation of star-shaped radial block copolymer system. However, they have not predicted how the number of branches affects the equilibrium morphology of the system. Nguyen et al. ${ }^{24}$ showed that the starshaped radial block copolymer having four branches was close to a random coil in shape. The star-shaped radial copolymers used in this study have the number of branches of 5.9 at most. From the theoretical and experimental results above mentioned, it can be assumed that for the copolymers the effect of number of branches is small and the thermodynamics for linear block copolymers can be applied to the present systems without any modification. Then, we can conclude that the equilibrium morphology is achieved in the films cast from the non-preferential solvent, T/M. We observed the cylindrical morphology in the $\mathrm{T} / \mathrm{M}$ films of SHB1, SBH2 and BSH1 (T/M is nonpreferential solvent) as shown in Figures $1-3$, though the morphology is not perfect for SBH1 and SBH2, suggesting that the ordered cylindrical morphology is the equilibrium one for the radial copolymers at the room temperature. Alward et al. ${ }^{15-17}$ have reported the ordered bicontinuous double-diamond structure as one of the equilibrium morphology for the linear and the radial block copolymers. However, we could find any trace of this morphology neither in the T/M films nor in the Cy films of the radial block copolymers.
The disordered cylindrical morphology (Figures 2(a) and 3(a)) is considered to be thermodynamically less stable than the ordered cylinder (Figure 1(a)), since it contains molecularly dispersed region (gray region in the picture) of the block copolymers. In the gray region, small $\mathrm{PB}$ particles, i.e., cores of the radial block copolymers, are dispersed uniformly in PS phase. In other words, this region is considered as well mixed phase in molecular size but segregated at sub-molecular level. As the size of the resolution of the electron microscopy has been reported ${ }^{25}$ to be $5-10 \mathrm{~nm}$, we may observe the core as a black particle, in principle, because the diameter of the core of molecule is estimated as larger than $10 \mathrm{~nm}$ for both SBH1 and SBH2. The thickness of the samples for transmission electron microscopy (TEM), however, makes the view gray.

SBH1 has almost the same molecular weight of branch and composition as, but is different in molecular chain structure from, BSH1. A complete build-up of the PB domains of SBH1 would be difficult for SBH1 at the critical concentration for the phase separation in preparing $\mathrm{T} / \mathrm{M}$ films, because the $\mathrm{PB}$ chains of SBH1 are at the center of a molecule. Therefore, the T/M film of SBH1 shows disordered cylindrical morphology due to an incomplete phase separation. The $\mathrm{T} / \mathrm{M}$ film of $\mathrm{SBH} 2$, which has almost the same composition as but larger molecular weight of branch than BSH1, also shows disordered cylinders.

The ordered lamellar and disordered lamellar morphology (Figures 1(b), 2(b) and 3(b)) are considered not to be equilibrium one for these radial block copolymers, by the following reasons. $\mathrm{Cy}$ is a preferential solvent of PB chains, and the star-shaped radial block copolymer solution separates into PS and $(\mathrm{PB}+\mathrm{Cy})$ phases at a critical concentration as the solvent evaporates. Then the lamellar morphology is formed at the concentration where the volume ratio of $\mathrm{PS}$ to $(\mathrm{PB}+\mathrm{Cy})$ is near unity. This morphology is the most sta- 
ble at the concentration, but becomes unstable as the solvent evaporates further. The morphology cannot change into cylinders but remain lamellar because of the high viscosity of the system. The Cy film of SBH1 shows the disordered lamellar morphology. The critical concentration for the phase separation is higher for the $\mathrm{Cy}$ solution of $\mathrm{SBH} 1$ than for those of SBH2 and of BSH1, because the length of PS chain of SBH1 is about a half as compared with those for $\mathrm{SBH} 2$ and BSH1. This is why the disordered lamellae occur in the Cy film of SBH1.

\section{Glass Transitions for the $S-B$ Radial Block Copolymers}

To clarify the relationship between the morphology and the viscoelastic properties for the $\mathrm{T} / \mathrm{M}$ and the Cy films of the copolymers, we examined the $E^{\prime \prime} v s$. temperature curves carefully and assigned them for several glass transitions of respective regions. They are as follows:

(1) glass transition of pure PS domains.

(2) glass transition of pure PB domains.

(3) glass transition of interphase region between PS and PB domains.

(4) glass transition of pinched-in lamellae.

(5) glass transition of PS domains in which the star-shaped radial block copoly mers are molecularly dispersed. We call this submolecular heterogeneous phase (SMHP).

The glass transtion of PS in pure PS domains is observed at $100-110^{\circ} \mathrm{C}$, and that of $\mathrm{PB}$ in pure $\mathrm{PB}$ domains at $-100-65^{\circ} \mathrm{C}$. The glass transition temperature of interphase region where the composition of the components continuously changes, also changes in the range from the $T_{\mathrm{g}}$ of pure PB to that of pure PS. The lamellae pinched in PS domains can not show the glass transition as pure PB, because they are thinner than the size of the resolution of dynamic viscoelastic measurements. The relaxation of the region should be strongly affected by the neighbouring PS domains. The $T_{\mathrm{g}}$ would be located at the range between the $T_{\mathrm{g}}$ 's of pure PS and PB; probably near $T_{\mathrm{g}}$ of PS. This transient region is formed in the course of the morphological transition from the lamellae to the cylinders under the condition of rapid change of concentration and viscosity of system. As mentioned before, the systems containing the radial block copolymers and $\mathrm{Cy}$ show the lamellae as the most stable morphology at a certain concentration. The morphology of the system tends toward cylinders from lamellae during evaporation of the solvent. The transient process, however, is prevented by the increasing viscosity of the system. Concludingly, the mor phological change proceeds from following three stages:

(1) The lamellar PB domains are pinched in PS domains, (2) the narrow parts of PB lamellae break and (3) cylinders are built up. Of course, the process cannot be completed, by high viscosity of the system and original lamellae, pinched-in lamellae and cylinders remain as transient state as seen from Figure 3 (b).

The glass transition of the submolecular heterogeneous phase (SMHS) which was observed as the gray parts in Figure 2 (a) and 3 (a). The region can be also considered as the PS domains plasticized by small PB particles and shows the only one $T_{\mathrm{g}}$ at $80^{\circ} \mathrm{C}$.

\section{Viscoelastic Properties for the Ordered Cy- lindrical morphology}

The T/M film of BSH1 (Figure 1(a)) shows this morphology. As can be seen from black circles in Figure 4, the $T_{\mathrm{g}}$ of the PS domains is at $100^{\circ} \mathrm{C}$, the $T_{\mathrm{g}}$ of the $\mathrm{PB}$ domains at $-100^{\circ} \mathrm{C}$, and the glass transition of the interphase spreads in a temperature range between the two $T_{\mathrm{g}}$ 's. The $T_{\mathrm{g}}$ of the PB domains is much lower than that of $\mathrm{PB}$ homopolymer $\left(-65^{\circ} \mathrm{C}\right)$, as mentioned before. This is mainly because the PB domains feel a negative pressure from PS domains. ${ }^{10}$ The negative pressure on PB domains can be generated by a 
difference in thermal expansion coefficients of PS and PB, when the temperature is lowered from the room temperature at which the sample film was prepared. The loss modulus $E^{\prime \prime}$ for T/M sample of BSH1 shows the lowest value as compared with the other samples (Figure 4-7), suggesting the most completed phase separation and the thinest interphase.

Viscoelastic Properties of the Disordered Cylindrical Morphology

The T/M films of SBH1 and SBH2 (Figures 2(a) and 3(a)) show this morphology. These samples show the $T_{\mathrm{g}}$ for the submolecular heterogeneous phase (SMHP) of PS at $80^{\circ} \mathrm{C}$, the $T_{\mathrm{g}}$ of $\mathrm{PB}$ domains at $-95^{\circ} \mathrm{C}$, as seen in Figure 6 . The reason why $T_{\mathrm{g}}$ of SMHP was observed at $80^{\circ} \mathrm{C}$ is not yet clear but it should be determined by an efficiency for plasticization in terms of concentration and size of $\mathrm{PB}$ chains.

The $T_{\mathrm{g}}$ of the PB domains in these films is also influenced by the negative pressure from the PS domains. As for the relaxation, $E^{\prime \prime}$ value for SBH1 and SBH2 are higher than that of the T/M film of BSH1. The disordered morphology is not thermodynamically stable, the PB domains do not aggregate sufficiently, and the samples of this morphology have thicker interphase region than that of $\mathrm{BSHI}(\mathrm{T} / \mathrm{M})$.

\section{Viscoelastic Properties for the Ordered \\ Lamellar Morphology}

The Cy films of SBH2 and BSH1 (Figures 1(b) and 2(b)) show this morphology. Open circles in Figures 4 and 5 show that the $T_{\mathrm{g}}$ of the PS domains at $110^{\circ} \mathrm{C}$, the $T_{\mathrm{g}}$ of pinched-in lamellae at $60^{\circ} \mathrm{C}$, and the $T_{\mathrm{g}}$ of the PB domains at $-75^{\circ} \mathrm{C}$. The $T_{\mathrm{g}}$ of pinched-in lamellae is observed as a shoulder in the $E^{\prime \prime} v s$. temperature curves. It should be emphasized that the glass transition of the pinched-in lamellar morphology occurs at a constant temperature ( $c a$. $60^{\circ} \mathrm{C}$ ), regardless of the molecular architecture and molecular weight. Though the reason has not yet been fully understood, it might be suggested that the pinched-in structure is much smaller than the size of resolution by viscoelastic measurements and that the concentration of pinched-in PB domains is constant. The $T_{\mathrm{g}}$ of the PB domains is higher than those of the ordered and the disordered cylinders, suggesting that the the lamellae feel less negative pressure from the PS domains. The ratio of interface to volume of the PB domains is smaller for the lamellar domains than that for the cylinders. The smaller the ratio is, the more easily the negative pressure might be relaxed; that is, the negative pressure is more easily relaxed in the lamellae than in the cylinders. This effect can explain the difference in the $T_{\mathrm{g}}$ of the PB domains of two morphology.

\section{Viscoelastic Properties for the Disordered} Lamellar Morphology

The disordered lamellar morphology which the Cy film of SBH1 (Fig. 3(b)) shows, should demonstrate the $T_{\mathrm{g}}$ for the PS domains at $100-110^{\circ} \mathrm{C}$, the $T_{\mathrm{g}}$ for SMHP of PS at $80^{\circ} \mathrm{C}$, and also the $T_{\mathrm{g}}$ of pinched-in lamellae at $60^{\circ} \mathrm{C}$. As seen from Figure 7 , the $T_{\mathrm{g}}$ 's at $60^{\circ} \mathrm{C}$ and $80^{\circ} \mathrm{C}$ are overlapped into single shoulder, because the temperatures are close. This corresponds to the broader peak of $E^{\prime \prime}$ of the $\mathrm{Cy}$ film of SBH1 in the higher temperature range in Figure 7.

The $T_{\mathrm{g}}$ of the PB domains is a little lower than those in the $\mathrm{Cy}$ films in the ordered lamellae. The film of this morphology contains the cylindrical parts where the PB domains feel more negative pressure, as mentioned before. Co-existence of cylinders and lamellae in the disordered lamellar morphology makes the $T_{\mathrm{g}}$ of PS a little lower than that in the ordered lamellar one.

\section{Viscoelastic Properties of Films of $\mathrm{SBH} 3$}

As previously mentioned for Figure 8 , the $E^{\prime}$ of the $\mathrm{T} / \mathrm{M}$ film of $\mathrm{SBH} 3$ keeps relatively higher value in the temperature range of $-75-80^{\circ} \mathrm{C}$. This means the morphology of 
the film is a bicontinuous one. Judging from the $\mathrm{S}-\mathrm{B}$ composition and the solvent $\mathrm{T} / \mathrm{M}$ used for casting, the morphology would be lamellar and stable at room temperature.

On the other hand, the behavior of the $E^{\prime} v s$. temperature curve for the $\mathrm{Cy}$ film of $\mathrm{SBH} 3$, indicates that the PB domains are highly continuous. This is because the solvent $(\mathrm{Cy})$ used for casting is preferential to $\mathrm{PB}$, and this morphology is that of the PS cylinders (or PS spheres) in PB matrix and might not be in equilibrium. The shoulders of the $E^{\prime \prime} v s$. temperature curves are observed at $50^{\circ} \mathrm{C}$ in both $\mathrm{T} / \mathrm{M}$ and $\mathrm{Cy}$ films of SBH3. For the Cy film of $\mathrm{SBH} 3$, the morphology can be frozen as PS cylinders or PS spheres by the evapolation of solvent before reaching an equilibrium (PS lamellae). The pinched-in PS lamellae exist because of the incomplete phase separation due to high viscosity of the system, to result in the $T_{\mathrm{g}}$ at $50^{\circ} \mathrm{C}$. Similar discussion previously made to explain the viscoelastic properties of the Cy films of BSH1, SBH1, and $\mathrm{SBH} 2$, in which the pinched-in lamellae were $\mathrm{PB}$.

In the case of $\mathrm{T} / \mathrm{M}$ film of $\mathrm{SBH} 3$, the lamellar morphology has achieved equilibrium. After the phase separation, aggregation of the PS domains via cylindrical morphology can easily occur as the solvent evapolates. In summary we can clarify that the $\mathrm{T} / \mathrm{M}$ and $\mathrm{Cy}$ films of SBH3 show four kinds of $T_{\mathrm{g}}$ 's (namely (1), (2), (3), and (4)), as mentioned previous section.

\section{Stress-Strain Behavior}

Comparing the stress-strain behavior of the Cy film with that of the $T / M$ film of the same copolymer in Figure 9, the Cy film of the lamellar morphology shows larger failure strain than the $T / M$ film of the cylindrical morphology. This implies that the $\mathrm{Cy}$ film contains highly continuous PB domains (lamellae) which can be under elongation after the PS domains were broken at the early stage of extention. However, the Young's modulus of the films are almost the same, be- cause the PS domains form the continuous phase in the both films. The Cy films of SBH1 and BSH1 show almost the same morphology and dynamic viscoelastic properties, as discussed before. The stress-strain behavior is quite different, however, as can be seen from Figure 10. In the $\mathrm{Cy}$ film of $\mathrm{BSH} 1$, PB lamellae contain the chain ends of molecules, according to the molecular structure. Such PB lamellae cannot keep the stress after the PS lamellar domains are broken down, and the breakage of the PS domains leads immediately to the failure of the film. On the contrary, the PB lamellae of SBH1 contain no chain ends. The distinct behavior of the $\mathrm{Cy}$ and the $\mathrm{T} / \mathrm{M}$ films of $\mathrm{SBH} 3$ is small yield stress and large failure strain, suggesting that the elongation of PB continuous domains is dominated at all extended points leading to a failure of the film.

Acknowledgment. We thank Yokkaichi Research and Development, Mitsubishi Monsanto Chemical Co. for the transmission electron micrographs of the film specimens. This research was supported in part by the Grant-in-Aid for Scientific Research (No. 61470101) from the Ministry of Education, Science and Culture, Japan.

\section{REFERENCES}

1. G. E. Molau, "Block Polymers," S. L. Aggarwal, Ed., Plenum Press, New York, N. Y., 1970.

2. D. J. Meier, "Block and Graft Copolymers," J. J. Burke and B. Weiss, Ed., Syracuse Univ. Press, New York, N. Y., 1973.

3. C. Sadron and B. Gallot, Macromol Chem., 164, 301 (1973).

4. J. F. Beecher, L. Marker, R. D. Bradford, and S. L. Aggarwal, J. Polym. Sci. (C), 26, 117 (1969).

5. T. Miyamoto, K. Kodama, and K. Shibayama, $J$. Polym. Sci., A-2, 8, 2095 (1970).

6. A. Beamish, R. A. Gordberg, and D. J. Hourston, Polymer, 18, 49 (1977).

7. G. H. Hsiue, M. Y. M. Ma, Polymer, 25, 882, (1984).

8. J. Diamant, D. Soong, and M. C. Williams, Polym. Eng. Sci., 22, 673 (1982).

9. T. Masuda, K. Kitamura, and S. Onogi, J. Soc. Rheol., Jpn., 8, 123 (1980). 
10. F. S. Bates, R. E. Cohen, and A. S. Argon, Macromolecules, 16, 1108 (1983).

11. C. Price, A. G. Watson, and M. T. Chow, Polymer, 13, 333 (1972).

12. E. Pedemonte, G. Dondero, F. de Candia, and G. Romano, Polymer, 17, 72 (1976).

13. L. K. Bi and L. J. Fetters, Macromolecules, 8, 90 (1975).

14. L. K. Bi and L. J. Fetters, Macromolecules, 9732 (1976).

15. D. B. Alward, D. J. Kinning, E. L. Thomas, and L. J. Fetters, Macromolecules, 19, 215 (1986).

16. D. J. Kinning, E. L. Thomas, D. B. Alward, L. J. Fetters, and D. L. Handlin, Jr., Macromolecules, 19, 1288 (1986).

17. E. L. Thomas, D. B. Alward, D. J. Kinning, D. C.
Martin, D. L. handlin, Jr., and L. J. Fetters, Macromolecules, 19, 2197 (1986).

18. H. L. Hsieh, J. Polym. Sci., 3, 181 (1965).

19. L. Leibler, Macromolecules, 13, 1602 (1980).

20. E. Helfand and Z. R. Wasserman, "Developments in Block Copolymers," I. Goodman, Ed., Applied Science Publishers, Ltd., London, 1982.

21. A. Khokhlov, Polymer, 22, 447 (1981).

22. J. Roovers, N. Hadjichristidis, and L. J. Fetters, Macromolecules, 16, 214 (1983).

23. M. O. de la Cruz and I. C. Sanchez, Macromolecules, 19, 2501 (1986).

24. A. B. Nguyen, N. Hadjichristidis, and L. J. Fetters, Macromolecules, 19, 768 (1986).

25. S. Akiyama, Kobunshi, 29, 819 (1980). 